\title{
Brittle rock failure in the Steg lateral adit of the Lötschberg base tunnel
}

Fabrice Rojat ${ }^{1,2}$, Vincent Labiouse ${ }^{1}$, Peter K Kaiser ${ }^{3}$, François Descoeudres ${ }^{1}$

1 Laboratoire de Mécanique des Roches, École Polytechnique Fédérale de Lausanne, Switzerland

2 Laboratoire Régional des Ponts et Chaussées, Toulouse, France

3 MIRARCO - Mining Innovation, Chair for Rock Mechanics and Ground Control, Laurentian University, Sudbury, Canada

This is the accepted author's version of an article protected by copyright.

The rights are held by Springer-Verlag Wien.

The final publication is available at http://link.springer.com.

http://link.springer.com/article/10.1007\%2Fs00603-008-0015-z

Article published in:

Rock Mechanics and Rock Engineering (ISSN 0723-2632)

April 2009, Volume 42, Issue 2, pp 341-359

Digital Object Identifier (DOI): 10.1007/s00603-008-0015-z 


\title{
Brittle rock failure in the Steg lateral adit of the Lötschberg base tunnel
}

\author{
By \\ F. Rojat ${ }^{1,2}$, V. Labiouse ${ }^{1}$, P.K. Kaiser $^{3}$ \& F.Descoeudres ${ }^{1}$ \\ 1 Laboratoire de Mécanique des Roches, École Polytechnique Fédérale de Lausanne, Swit- \\ zerland \\ 2 Laboratoire Régional des Ponts et Chaussées, Toulouse, France \\ 3 MIRARCO - Mining Innovation, Chair for Rock Mechanics and Ground Control, Lauren- \\ tian University, Sudbury, Canada
}

\begin{abstract}
Summary
During the crossing of brittle rock formations at the Lötschberg base tunnel, failure phenomena have been observed both at the tunnel face and at the walls. A detailed analysis has been undertaken to explain these behaviours, based on the recent developments of Canadian research on brittle failure mechanisms. At the tunnel walls, a very good agreement is found between calculated and observed damage and between two prediction methods i.e. a semi-empirical failure criterion and elastic calculations with the "brittle Hoek-Brown parameters". Near the face, due to the 3D nature of the stress conditions, some limitations of these approaches have been highlighted, and the growth of wall failure has been analysed. This research allowed a better understanding of the brittle rock mass behaviour at the Lötschberg base tunnel and showed that brittle failure processes dominate the behaviour of deep, highly stressed excavations in massive to moderately jointed rock. It also illustrates where improvements to the adopted approaches are required.
\end{abstract}

Keywords : tunnel, Lötschberg, brittle failure, brittle Hoek-Brown parameters, high stress, brittle rock.

\section{Introduction}

In the last several decades, the growing need for fast, reliable and cost-effective transport systems has led to new challenges in tunnel design and construction. In particular, deep tunnels such as the Lötschberg or the Gotthard base tunnels are being built in Switzerland through the Alps and require facing specific geological and geo-mechanical challenges under conditions of high stress. In this context, issues related to brittle failure and ground control, historically encountered in deep mines, are now of particular interest for tunnels.

\subsection{The Lötschberg base tunnel and the Steg lateral adit}

The Lötschberg base tunnel is located in Switzerland and links Frutigen, in the Lanker Valley, to Raron, in the Rhône Valley. Combined with the existing Simplon tunnel, it constitutes the first transalpine rail axis with end-to-end enlarged cross-sections and provides a direct link between Germany and Italy through Switzerland. The tunnel itself is 34.6 kilometres long and consists for most parts of two tubes (diameter around $9.40 \mathrm{~m}$ ) at a distance of $40 \mathrm{~m}$ from each other, linked together every $333 \mathrm{~m}$ through a perpendicular gallery. Two excavation techniques are used, i.e. tunnel boring machines (TBM) and drill \& blast. In its south part, the tunnel is driven over nearly 10 kilometres under more than $1000 \mathrm{~m}$ of cover. The maximum overburden is as high as $2000 \mathrm{~m}$.

This paper is centred on phenomena that occurred within the Steg lateral adit, located at the south end of the tunnel. Along this line, the overburden progressively increases from the portal to nearly $2000 \mathrm{~m}$ just after the intersection with the main track and consists of massive to moderately jointed rock formations mainly consisting of gneiss, granodiorite or granite. A rough description of the local geology is presented on Figure 1. As this part of the tunnel was TBM excavated, the surrounding rock underwent little disturbance, which allowed interpreting the field data in terms of rock-mass behaviour. When necessary, bolting, meshing and shotcrete were the main support systems. 


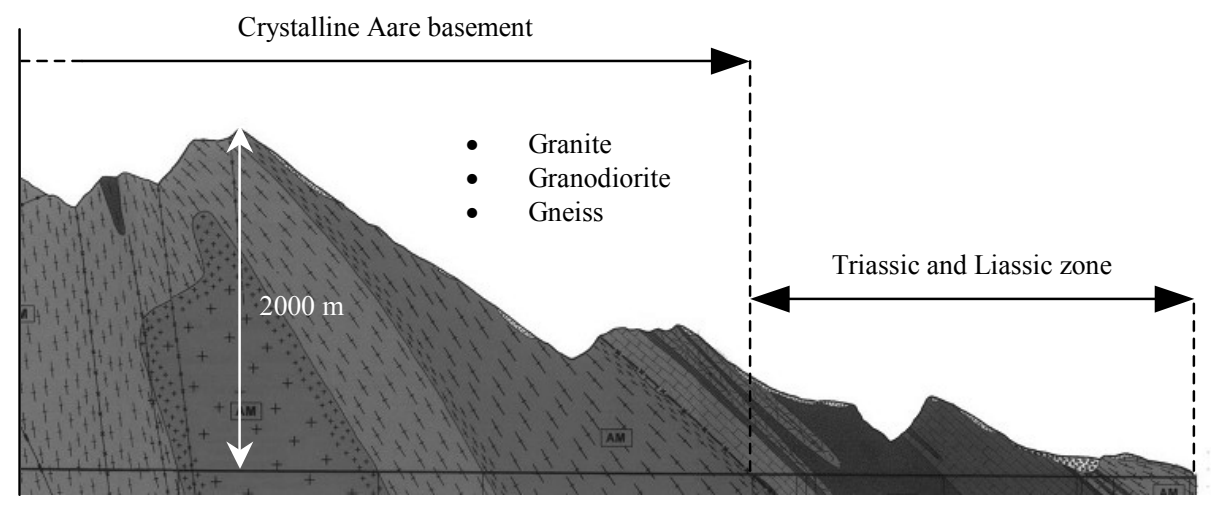

Fig. 1. Geological model of the South part of the Lötschberg tunnel

\subsection{Observed phenomena in the Steg lateral adit}

Two different kinds of problems were reported during the excavation of the Steg lateral adit. Their typology, depicted below, was established through field surveys and meetings with the design office IngenieurGemeinschaft WestSchweiz (I.G.W.S.) in charge of the executive studies, with the project geologists and with workers in the field.

A first phenomenon, reported by field workers as "block formation" in front of the TBM head, consisted of blocks with a predominantly slab-like shape (Kaiser, 2005) loosening from the tunnel face. They jammed conveyor intake, provoked frequent disk and bearing failure, caused more wear and tear on TBM head and discs, thus increasing maintenance requirements and costs and reducing rate of advance. When these instabilities appeared, instead of showing a flat face with clear marks from the cutters, the tunnel face was quite irregular and the cutter tracks were only visible in sections without breakouts. A high variability was noticed in the intensity of the phenomenon: sometimes almost the entire face was damaged (Kaiser 2005) but often only a small proportion failed.

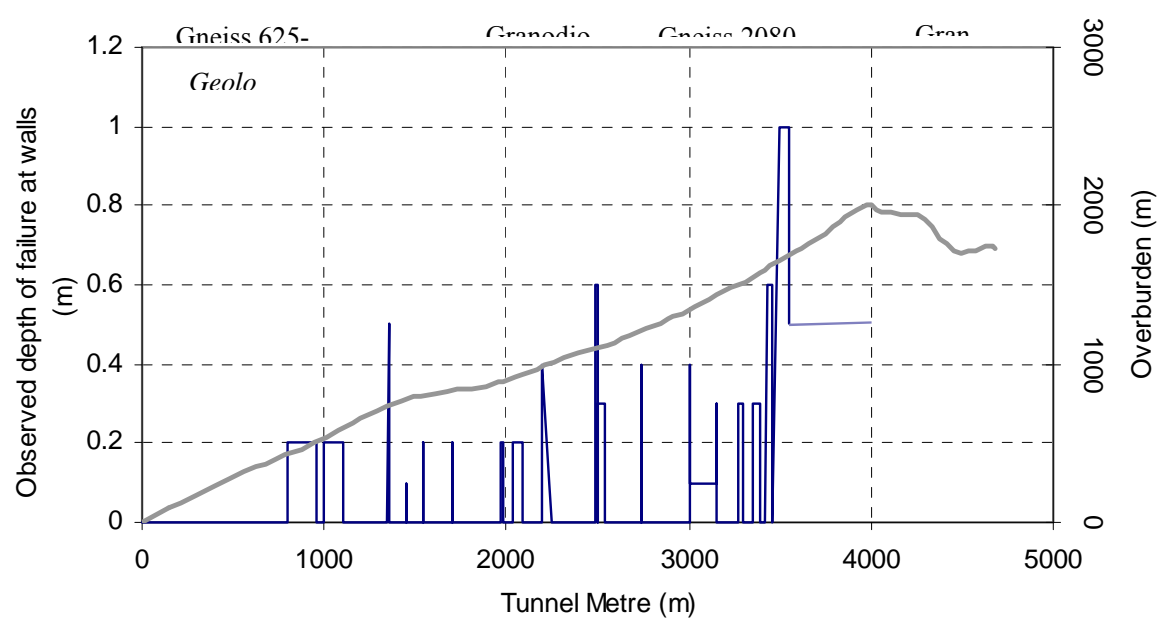

Fig. 2. Inventory of the failure zones at tunnel walls along the Steg lateral adit

The second observed phenomenon consisted of scales of low thickness peeling off the walls inside the excavation. When high overburden depth was encountered, around station 3000 and more, deep notches (up to about $1 \mathrm{~m}$ locally) could appear, typically in a symmetrical pattern. At moderate stress levels, failure was often non-symmetric, i.e. one-sided. Most often, these onion-skinning and notching phenomena were noticed in zones of strong massive rock. The shape of the notches appeared to be independent of the natural, steeply dipping foliation planes. Some strong acoustic phenomena were also reported, but violent ejections of blocks were rarely observed. Apparently, most energy releases occurred within 4 meters from the face i.e. within the TBM shield; however, some delayed strainburst/spalling was observed, with failure zones appearing after some time, especially during longer stoppages of the TBM. In some cases, the 
notches prevented the grippers from having a good contact with the rock mass, which caused some output losses.

To quantify this second phenomenon, a systematic inventory of the failure zones with a rough estimate of their depth was performed in the field along the first 4000 meters of the Steg track. The main results in terms of observed depth of failure are given in Figure 2. As can be seen, up to TM 3500 approximately, the spalling process was generally localised or limited to distinct zones. Overall, about $30 \%$ of the tunnel from the location with first signs of spalling at Station 800 onwards showed obvious signs of spalling.

\subsection{Context of the research}

The brittle behaviour of rock under high stress is a quite common statement for geo-engineers. However, the precise understanding of its consequences on underground works is still a topical problem. In recent years, the research carried out at the Canadian AECL Underground Research Laboratory, Pinawa, Manitoba, Canada, strongly contributed to the understanding of stress-driven brittle behaviours by proposing new failure processes and various criteria for depth-of-failure assessment.

In this context, the research performed at the Rock Mechanics Laboratory of the Swiss Federal Institute of Technology of Lausanne (E.P.F.L.), Switzerland, with the expert contribution of the co-author, aimed at analysing whether the failure criteria developed from the Canadian brittle rock failure research programme and field experience could describe the phenomena reported in the Steg lateral adit of the Lötschberg basis tunnel (Rojat et al., 2002). This paper summarises the main steps and results of the study and highlights some of the advantages and limitations of the method.

\section{Review of the theoretical concepts of brittle failure around tunnels}

\subsection{Qualitative overview of stress-induced brittle failure}

Many researchers have shown that the brittle failure process initiates with the growth of microcracks in the direction of the maximum applied load or principal stress. The Griffith theory (1924) indicates that an elliptic crack oriented with a critical angle tends to extend in the direction of the major principal stress. Likewise, Horii and Nemat-Nasser (1985) described a mechanism (“crack-kinking”) by which a crack, initially inclined to the principal stresses, would extend in the direction of the major principal stress. In their experiments with compression of resin, they showed that the presence of a free surface had the effect of inducing crack-kinking in the vicinity of the free surface and that the cracks then followed more or less the free-surface contour.

In tunnels, induced cracking initiates as a result of the removal of the confining stress and the loading by tangential stresses. The cracks then extend parallel to the walls, forming slabs of rock that may bulk, buckle or explosively break. Intuitively, one would expect for a massive rock that these stress-induced damage phenomena would occur when the rock is loaded beyond its unconfined compressive strength. In fact, as explained below, the rock-mass around an underground opening undergoes specific stress and strain conditions, which causes failure to occur at much lower threshold values.

\subsection{The mechanisms of brittle failure in laboratory tests and near underground openings}

In laboratory compression tests, crack growth typically starts around 0.3-0.5 $\sigma_{\mathrm{c}}$ and increases until macroscopic failure takes place. Kaiser et al. (2000) or Diederichs et al. (2004) explain that the conventional models like the Hoek-Brown and the Mohr-Coulomb strength envelopes assume that both cohesion and friction contribute to the peak strength and are mobilised instantaneously and simultaneously during the test (sliding crack model). For brittle rocks, this interpretation is valid at high confinement levels, when the rock behaves in a ductile manner. However, at low confinement, despite the compressive stress field, tensile failure is generated in the sample due to microscopic rock heterogeneity (Diederichs et al., 2004). As a consequence, crack dilation occurs after the damage initiation stage, which inhibits the coincidental mobilisation of the cohesion and the frictional strength component. As an example, Diederichs et al. (2000) demonstrated through calculations with a bonded particle model that in the case of brittle rocks, the shear cracks were dominated by a ratio of $50: 1$ by tensile cracking. Hence, the frictional strength is only mobilised when the rock is sufficiently damaged to become essentially cohesionless. Failure is driven by a cohesion-loss process and accelerates when a critical crack density is reached (coalescence). Most importantly, due to this process the normal stress is highly variable and the shear strength 
component $\left(\tau=\sigma_{\mathrm{n}} \tan (\varphi)\right)$ distribution is also variable, leading to internal strength heterogeneity (Kaiser et al. 2000).

In laboratory samples, damage initiation and coalescence happen at distinct stress levels, respectively around 0.4 and $0.8 \sigma_{\mathrm{c}}$ for granitic or gneissic rock types (where $\sigma_{\mathrm{c}}$ is the uniaxial compressive strength of the intact rock). The coalescence stage also corresponds to the long-term laboratory strength of the sample.

Around an underground opening, this behaviour is significantly modified (Kaiser et al., 2000). Instead of a simple monotonic loading path, the rock mass in the field undergoes a specific stress-strain history, which causes the stress level for crack coalescence to drop to a much lower value. Typically, in massive and moderately jointed hard rock masses, brittle failure occurs around 0.3-0.5 $\sigma_{c}$, i.e. near or slightly above the stress level required for damage initiation.

Consequently, according to Diederichs et al. (2004), the laboratory level of crack interaction should be considered as an upper bound for rock strength while the level of damage initiation should be regarded as a lower bound. In the field, the obtained brittle rock-mass strength then depends on various factors such as rock brittleness (Hajiabdolmajid et al., 2002/2003), pre-existing damage, rock-mass heterogeneity and jointing, feedback confinement due to size effects or stress rotation, and more.

\subsection{How to assess brittle rock-mass failure in the field?}

To translate these findings into quantitative data, the collaborating researchers (Martin et al. 1999, Diederichs et al. 2000, and Kaiser et al. 2000) propose a bilinear cut-off of the classical Hoek-Brown failure envelope, as shown in Figure 3. A first level, corresponding to the damage initiation envelope, can be described through the so-called "Hoek-Brown brittle parameters" (Martin et al. 1999):

$$
\boldsymbol{m}=\mathbf{0} \text { and } \quad \boldsymbol{s} \approx 0.11 \quad\left(\Leftrightarrow \sigma_{1}-\sigma_{3} \approx \sigma_{\mathrm{c}} / 3\right)
$$

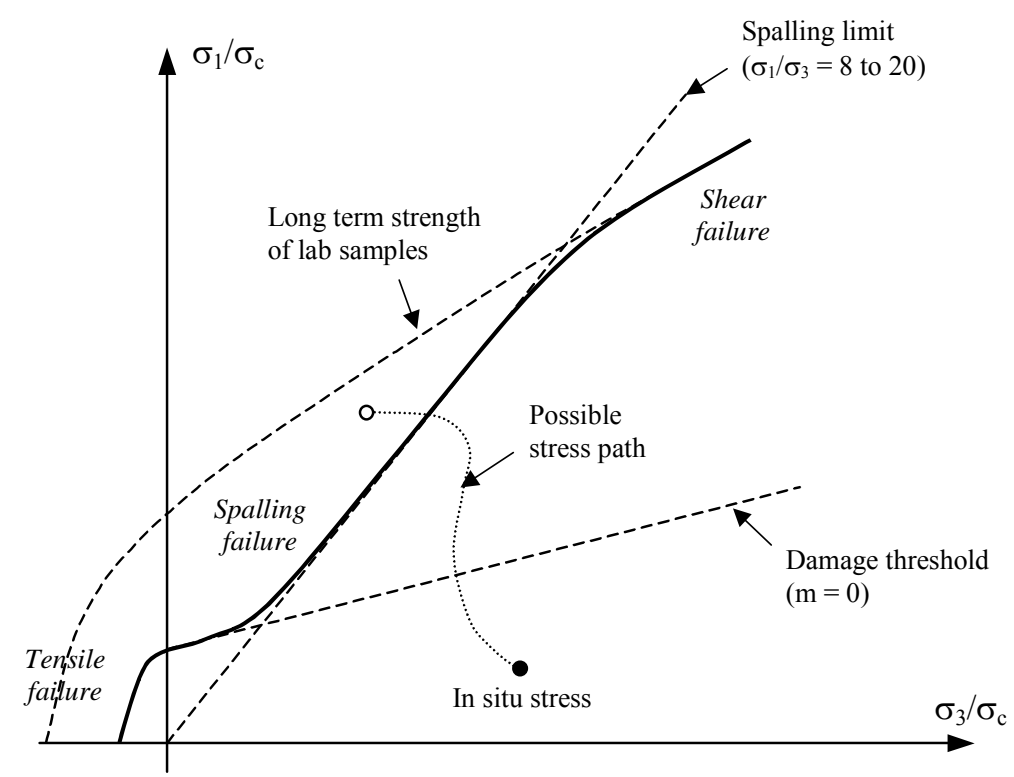

Fig. 3. Bilinear cut-off of the classical Hoek-Brown failure envelope and associated failure modes (modified from Diederichs, 1999 and Kaiser et al., 2000)

The second threshold, called "spalling limit", is defined by $\sigma_{1} / \sigma_{3}=8-20$, depending mainly on rockmass heterogeneity and jointing. When increasing the confinement level, this line allows a progressive link between the lower bound corresponding to damage initiation and the classical Hoek-Brown criterion that becomes valid again when crack opening (and tensile failure) is prevented at higher confinement (to the right of the spalling limit).

In the case of a tunnel or a mine, Martin (1997), Eberhardt (2001) and Diederichs et al. (2004) showed that the loading path could be particularly complex, involving stress increase, decrease and rotation (see stress path in Figure 3 for example). Typically, damage initiates in the field near the advancing tunnel face and progressively increases until macroscopic phenomena occur at about 0.1-0.5 radii behind the face. The bilinear failure envelope may be crossed at various positions in the $\sigma_{1}-\sigma_{3}$ space, causing 
different kinds of failure. Spalling phenomena are encountered when both the damage limit and the spalling limit are exceeded, under the "long term lab strength" limit (see Figure 3). In these cases, an important strength reduction appears.

The bilinear Hoek-Brown failure envelope cut-off can be used to predict the extent of brittle failure in the field. For example, Martin et al. (1999) showed through elastic numerical modelling and comparison with field data that the maximum depth of brittle failure around a tunnel in massive to moderately fractured rock could be well estimated by using a constant deviatoric stress criterion $\sigma_{1}-\sigma_{3} \approx \sigma_{\mathrm{c}} / 3$ (damage initiation level).

Alternatively, for near circular excavations, Martin et al. (1999) propose that the depth of failure near the wall can be obtained in a semi-empirical equation, established from the analysis of various case histories:

$$
\frac{d_{f}}{a}=1.25 \frac{\sigma_{\max }}{\sigma_{c}}-0.51 \quad( \pm 0.1)
$$

where : $d_{f}=$ depth of failure

$\mathrm{a}=$ tunnel radius

$\sigma_{\max }=3 \sigma_{1}{ }^{0}-\sigma_{3}{ }^{0}$ (from 2D elastic Kirsch solutions) with $\sigma_{1}{ }^{0}$ and $\sigma_{3}{ }^{0}$ being the major and minor far-field stresses respectively

$\sigma_{\mathrm{c}}=$ unconfined compressive strength of intact rock

By data interpretation from many tunnels in different rock types from locations around the world, the collaborating researchers found a good agreement between field data and the results from both analyses with brittle Hoek-Brown parameters (Martin et al. 1999) and the semi-empirical equation.

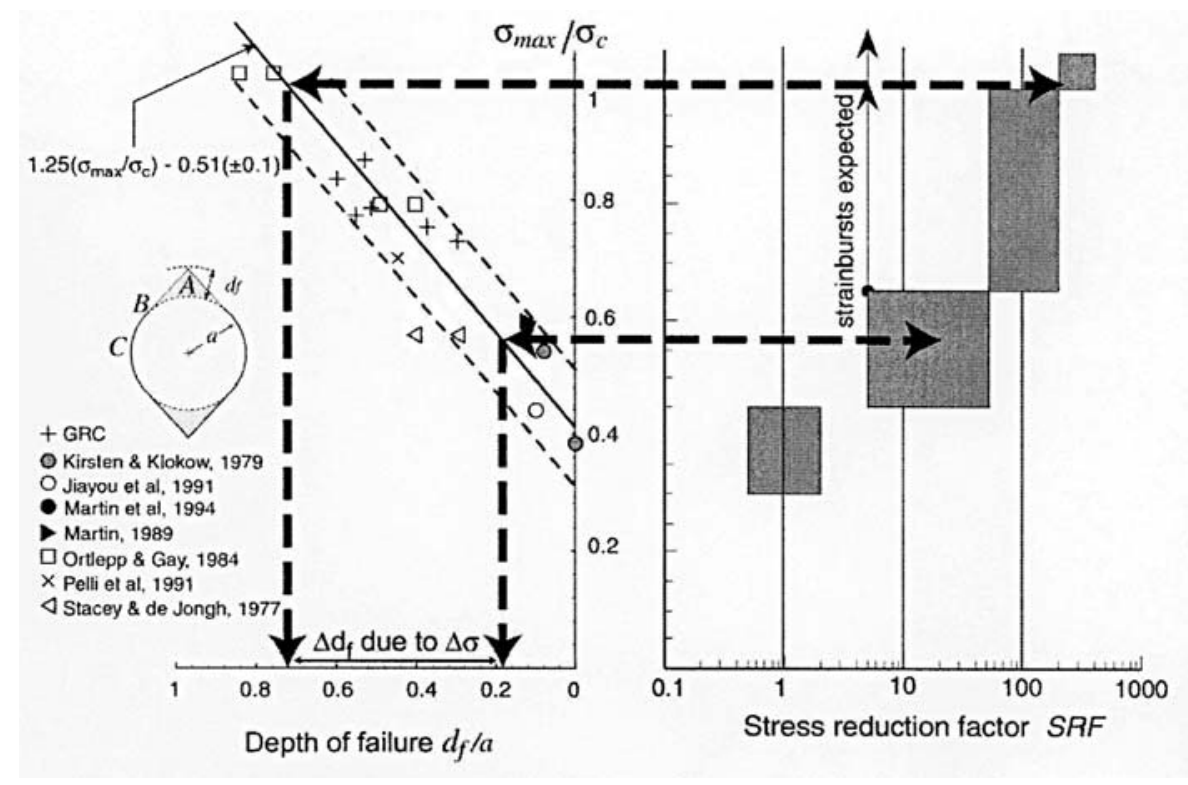

Fig. 4. Relationship between depth of failure, stress level and Barton's stress reduction factor SRF (after Kaiser et al., 2000)

As a complementary analysis, the stress reduction factor (SRF) tables from Barton's design chart (1994) might be used to assess the expected intensity of failure (Kaiser et al., 2000). As can be seen on Figure 4, at a stress level of $0.30-0.45$, when the depth of failure is close to zero according to equation (1), the SRF is near unity. No failure and thus no rock bulking is to be expected. At intermediate SRF values (5-50) or a stress level of 0.45-0.65 $\left(\mathrm{d}_{\mathrm{f}}=0-0.3\right.$ tunnel radius), modest spalling may appear. After this threshold, violent failure in the form of strainbursts is to be anticipated in hard and brittle rocks.

The application of these various failure approaches to the case of the Lötschberg tunnel are discussed in the rest of this paper. As in situ far-field stresses and intact rock uniaxial compressive strength are the main parameters of the presented models, the following section is centred on how these parameters were obtained in our analysis. 


\section{Evaluation of stresses and rock properties in the Steg lateral adit}

\subsection{In situ stress field assessment}

For the assessment of tunnel stability, the in situ stress magnitude and orientation constitutes a first dominant parameter set. However, despite the importance of these data in any rock-mechanics problem, few reliable stress measurements are usually available. In the case of the Lötschberg base tunnel, Steg lateral adit, the stresses had to be inferred from 3D stress analyses, assuming elastic rock behaviour, ignoring the influence of tectonic stresses and of heterogeneity of the rock mass. This approach was conducted by the design office I.G.W.S. (1995) during the project studies. An example of the topographic model and of the results along the Steg lateral adit are presented in Figure 5. In 1995, these calculation results were compared with stress measurements under the Gasteretal Valley, revealing good agreement. However, it must be emphasised that no comparison had been performed in the South part of the tunnel (along Steg track in particular).

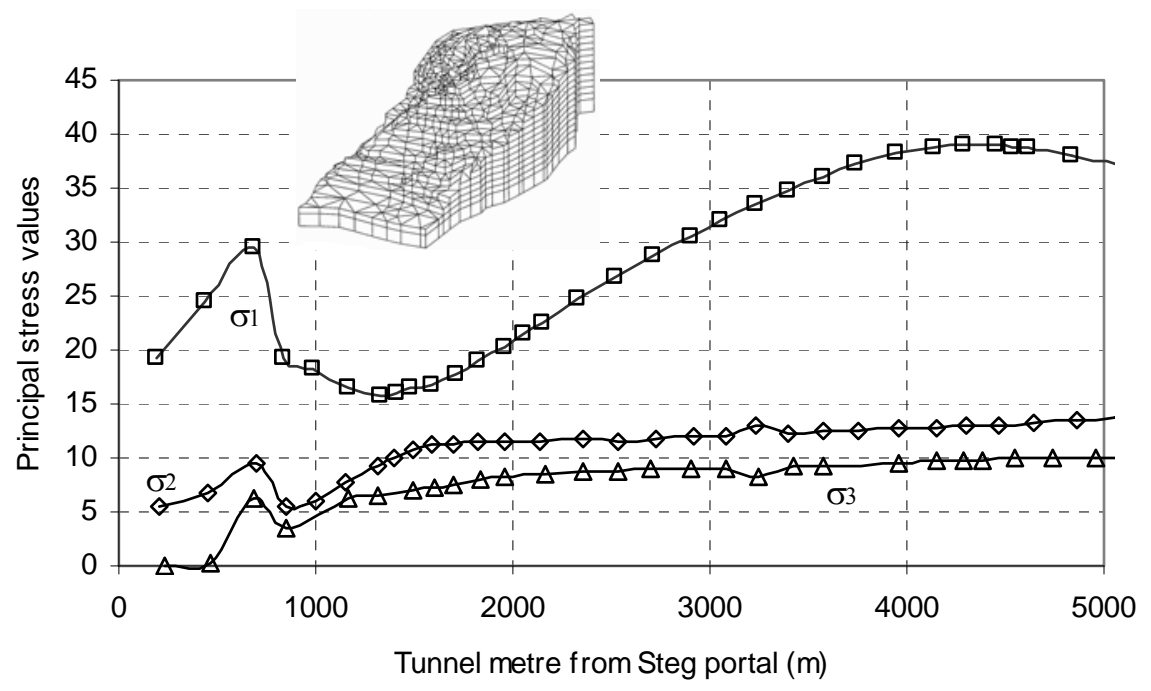

Fig. 5. 3D topographic model and principal far-field stress values from IGWS (1995) (note: dip after initial peak is due to a side valley effect)

From these 3D topographic analyses, it was found that, after TM 1000 along the Steg track, the principal stresses plotted in Figure 5 could be considered reasonably well aligned with the tunnel main direction X-Y-Z. Consequently, the following notations were used in the study:

$\sigma_{Z}{ }^{0}$ : principal far-field stress, parallel to the vertical (major)

$\sigma_{X}{ }^{0}$ : principal far-field stress, parallel to the tunnel axis

$\sigma_{Y}{ }^{0}$ : principal far-field stress, perpendicular to $\sigma_{X}{ }^{0}$ and $\sigma_{Y}{ }^{0}$

The principal stress values inferred from the IGWS topographic calculations in plane Y-Z along the Steg track axis are summarised in Figure 6. They allowed the evaluation of the maximum tangential stress around the circular opening $\left(\sigma_{\theta \max }=3 \sigma_{Z}{ }^{0}-\sigma_{Y}{ }^{0}\right)$, which is used subsequently in depth-of-failure predictions.

It is important to emphasise the limitations of this approach. In particular, it is widely recognised today that in-situ stress predictions based on elastic models considering only topography can be very inaccurate, since tectonic effects, adjustments along weak fault zones, stress concentrations in rocks of high stiffness, etc. are ignored. To clarify this point, a flat-jack test was performed at TM 3700, which yielded a longitudinal far-field stress of $\sigma_{\mathrm{X}}{ }^{0}=15 \mathrm{MPa}$ instead of $9 \mathrm{MPa}$ predicted by the topographic model. Even if other factors have to be considered, this observation may be related with a possible tectonic stress, as the base tunnel remains very near from the valley level : in particular, the world-stress map (Müller et al., 2004) clearly suggests that the major horizontal stress could be aligned with the Lötschberg base tunnel axis (SSW to NNE). The axial stress, however, has little influence on wall spalling as long as it is significantly lower than 0.3 UCS (see further). Moreover, a simple elastic calculation 
would show that a longitudinal far-field stress of $9 \mathrm{MPa}$ at TM 3700, combined with $\sigma_{\mathrm{Z}}{ }^{0}=38 \mathrm{MPa}$ and $\sigma_{\mathrm{Y}}{ }^{0}=13 \mathrm{MPa}$, would mean tensile longitudinal stress in tunnel roof and floor after excavation. Since no opened cracks were observed in the tunnel, the measured value of $15 \mathrm{MPa}$ may seem more realistic. As no other results were available, a parametric study on the $\sigma_{X}{ }^{0}$ value was performed (see Section 4).

\subsection{Uniaxial compressive strength assessment}

For the assessment of tunnel stability, the unconfined compressive strength of the intact rock as determined in the laboratory constitutes a second controlling parameter according to the Canadian models.

In this research project, a detailed analysis of the test results was necessary in order to account for sample disturbance. Indeed, when sampling rock that may be prone to brittle failure, long before disking is observed in the core, the effect of stress concentrations at the end of the borehole causes sample damage (Martin and Stimpson, 1994). When sampling within a metre or two of a highly stressed tunnel wall, this effect may be aggravated by the incipient spalling of the tunnel wall. Hence, it is possible (Kaiser, 2002) that some samples taken from the Lötschberg base tunnel are damaged and thus may not be representative of the intact rock properties.

This effect was observed in a series of laboratory tests with acoustic emission monitoring that were performed by the E.P.F.L. research team on granite samples from station 3900 in the tunnel. Both the uniaxial compressive strength and the damage initiation level were found to vary with the distance from the tunnel wall. In particular, on the samples taken at a great distance from the tunnel wall, crack initiation occurred around 0.4 UCS indicating no or little pre-existing damage. On the other hand, at shallower depths, the UCS was much lower and a Kaiser-effect was observed, with a damage initiation level detected later during the test, at 0.7 to 0.9 UCS. However, no quantitative correlation between depth and damage could be inferred from these test results. In fact several other factors should have been considered such as the natural dispersion of test results, coring effects, orientation of foliation, variations in rock granulometry and the brittleness index (Hajiabdolmajid et al., 2002).

Consequently, a statistical analysis was performed on the 84 UCS values available for this study, in order to determine the most probable "intact strength" of the rock formations encountered along the Steg lateral adit. After removing the lowest UCS values for the above-explained reasons, the classification presented in Table 1 was obtained.

Table 1 Values of the uniaxial compressive strength for the four main rock types encountered along the Steg track.

\begin{tabular}{lllll}
\hline Rock type & $\begin{array}{l}\text { UCS // to } \\
\text { foliation } \\
(\mathrm{MPa})\end{array}$ & $\begin{array}{l}\text { UCS } \perp \text { to } \\
\text { foliation } \\
(\mathrm{MPa})\end{array}$ & $\begin{array}{l}\text { All values } \\
\text { together } \\
(\mathrm{MPa})\end{array}$ & $\begin{array}{l}\text { Standard } \\
\text { deviation } \\
(\mathrm{MPa})\end{array}$ \\
\hline Gneiss TM 625-1610 & 90 & 100 & 95 & 15 \\
Gneiss TM 2080-2170 & 130 & 170 & 150 & 28 \\
Granodiorite & 110 & 180 & 140 & 35 \\
Granite & 200 & 200 & 200 & 25 \\
\hline
\end{tabular}

This table clearly shows that in gneiss and granodiorite formations, the orientation of foliation with respect to the main load direction may play a significant role in the analysis of rock mechanical behaviour. However, since foliation in large parts is subvertical and dipping generally in the direction of the tunnel, the average or UCS $\perp$ may be the most representative (UCS // is meaningful for the analysis of the tunnel face). Furthermore, the standard deviations in Table 1 indicate that a significant variability in UCS values may be expected along the tunnel. Then, as in the context of this research only the average values have been used (column "All values together"), the natural dispersion of rock strength will have to be considered when comparing theoretical analyses and field observations.

\section{Analysis of wall stability}

Rock behaviour at the tunnel walls can now be analysed with the models presented in Section 2, using the parameters from Section 3. 


\subsection{Application of the semi-empirical failure criterion}

As mentioned before, for a circular excavation, the depth of failure can be obtained by using the semiempirical Equation (1). Exploiting the stress data from I.G.W.S. (1995) presented in Figure 5, an evaluation of the depth of failure along the tunnel has been performed. Furthermore, the systematic inventory in the field of the failure zones - with a rough estimate of their depth - along the first 4000 meters from Steg portal allowed comparison between calculated and measured depths of failure. The corresponding results are plotted in Figures 6 and 7.

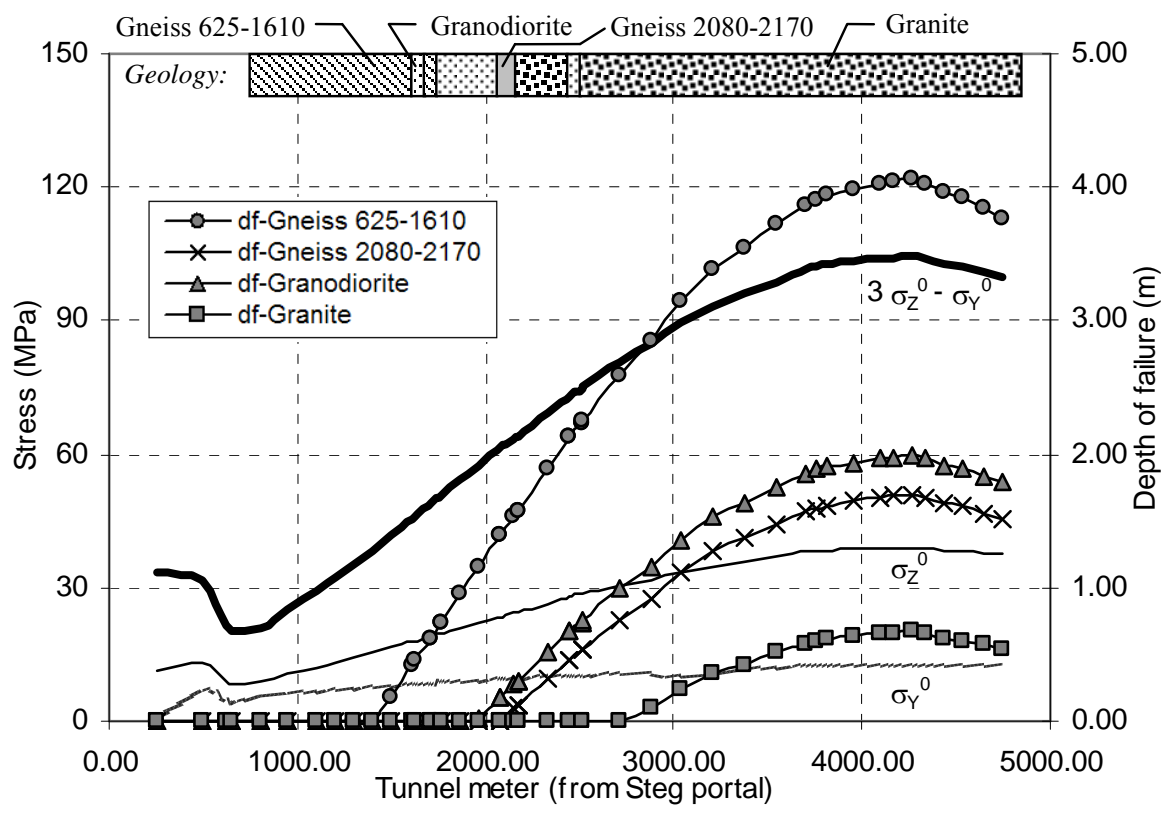

Fig. 6. Principal stresses in plane OYZ (tunnel cross-section) and associated $\sigma \mathrm{max}$ as well as theoretical depths of failure (df) for Gneiss 625-1610 (UCS = 95 Mpa), Gneiss 2080-2170 (UCS = 150 Mpa), Granodiorite (UCS = 140 Mpa) and Granite (UCS = 200 Mpa), along the Steg lateral adit

For the four rock types identified in Section 3.2, Figure 6 shows what the predicted depth of failure would be if the Steg track was consistently crossing the four rock types. Logically, in rocks with lower UCS values (Gneiss 625-1610 e.g.) failure begins earlier and goes deeper than in rocks with higher UCS values. However, this analysis only makes sense when it is combined with the observed geology and compared with the real failed zones, as plotted in Figure 7. It must be emphasised that, for a tunnel radius of $5 \mathrm{~m}$, the uncertainty on the semi-empirical failure criterion leads to a variation of $\pm 35 \mathrm{~cm}$ on the predicted depth of failure (with about $90 \%$ uncertainty). Furthermore, the anticipated variability in in-situ stress (Martin et al., 2005), and most importantly, the variability in rock strength (UCS), increases the uncertainty in the prediction (Kaiser, 2006). For example, for a mean UCS of $200 \mathrm{MPa}$ (granite) at the deepest point in the tunnel (at $\sigma_{\max }=105 \mathrm{MPa}$ ), the depth of failure ranges, according to Equation (1), from 0.37 to $1.20 \mathrm{~m}$ (with a mean of $0.73 \mathrm{~m}$ ) for a standard deviation of $25 \mathrm{MPa}$ in UCS, as encountered in this testing programme, and with $68 \%$ uncertainty ( \pm 1 standard deviations if normal distribution).

As a consequence, considering the values plotted in Figures 6 and 7 (often $<50 \mathrm{~cm}$ ), the comparison should base on the location of the observed failure and the relative severity of failure. Furthermore, this depth of failure was sometimes difficult to assess in the field as shotcrete had been applied in the most damaged zones; in particular between TM 3500 and 4000 where the horizontal line in Figure 7 indicates an estimated mean value. 


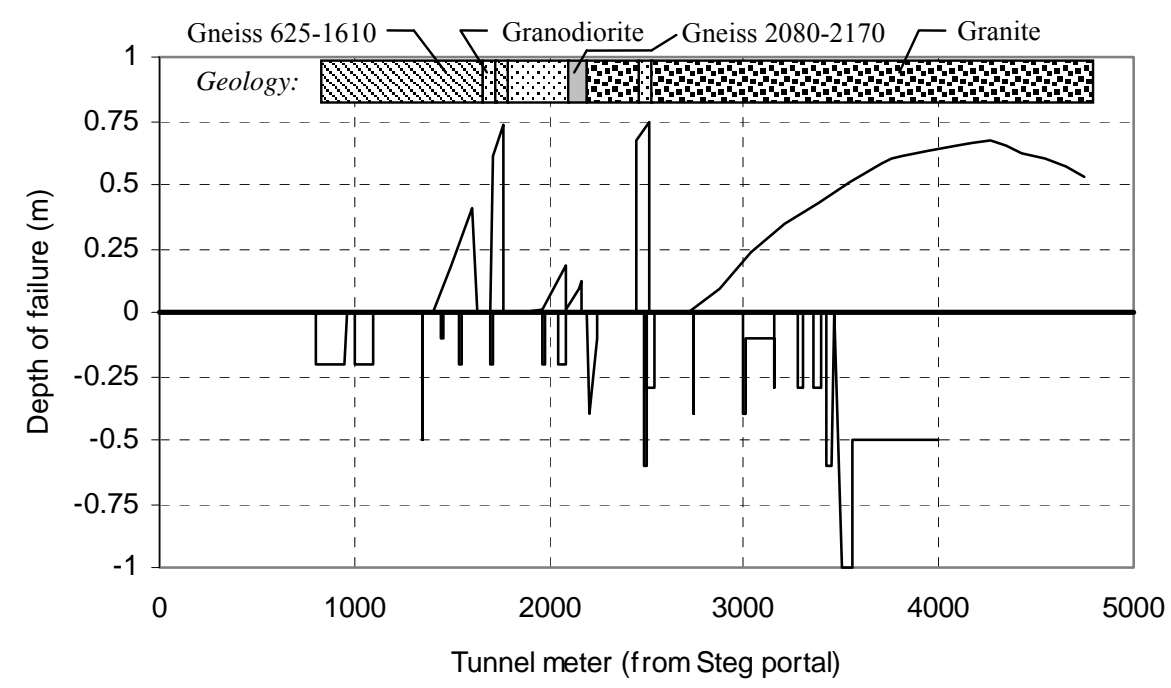

Fig. 7. Comparison between observed failure and predicted by the semi-empirical criterion along the Steg lateral adit, taking into account the real geological conditions

In general, good agreement is found between the observed and predicted failure zones, even though the implied direct relationship with the four rock types may be overly simplistic as the expected local variations in rock properties (see Section 3.2) are clearly dominating brittle failure (Martin et al. 2005). In particular, the following observations can be made:

- failure in granite is predicted to begin around TM 2700, which is precisely the case ;

- in gneiss and granodiorite most observed failure zones are predicted by the semi-empirical failure criterion. However, the damages observed between TM 800 and 1100 are not explained with this approach. These failed zones most probably correspond to particular local conditions (major principal stress inclined to the vertical, specific rock mass properties and/or discontinuity orientation), which tends to be supported by the fact that failure was mostly non-symmetric (one-sided) in this area.

This analysis seems to confirm that most of the wall failures observed along the Steg track can be described by classical spalling processes. Consequently, the microscopic behaviour of the encountered rocks is expected to fit well with the brittle failure mechanisms presented in Section 2: tensile cracks accumulate until the rock mass spalls when the cracks have reached a sufficiently high density such that coalescence can create near surface parallel slabs (Kaiser et al., 2000). According to Martin et al. (1999), this process can be approximated well by numerical models using brittle Hoek-Brown parameters.

\subsection{Use of the brittle Hoek-Brown parameters}

The analysis was performed with the 3-D finite element software Z_Soil (2002). The model shown in Figure 8 was composed of more than 4000 hexahedral continuum elements; the boundary conditions were modelled by "infinite elements" (i.e. elastic "springs" at the boundary of the tunnel), thus allowing a smaller 3-D model, reduced calculation time and limited boundary effects. The far-field stress conditions were taken from the I.G.W.S. (1995), as explained in Section 3.1. The methodology proposed by Martin et al. (1999) was used, i.e. elastic analyses with plotting of the brittle Hoek-Brown criterion $\mathrm{m}=0, \mathrm{~s}=$ 0.11 , to determine the anticipated depth of failure. 


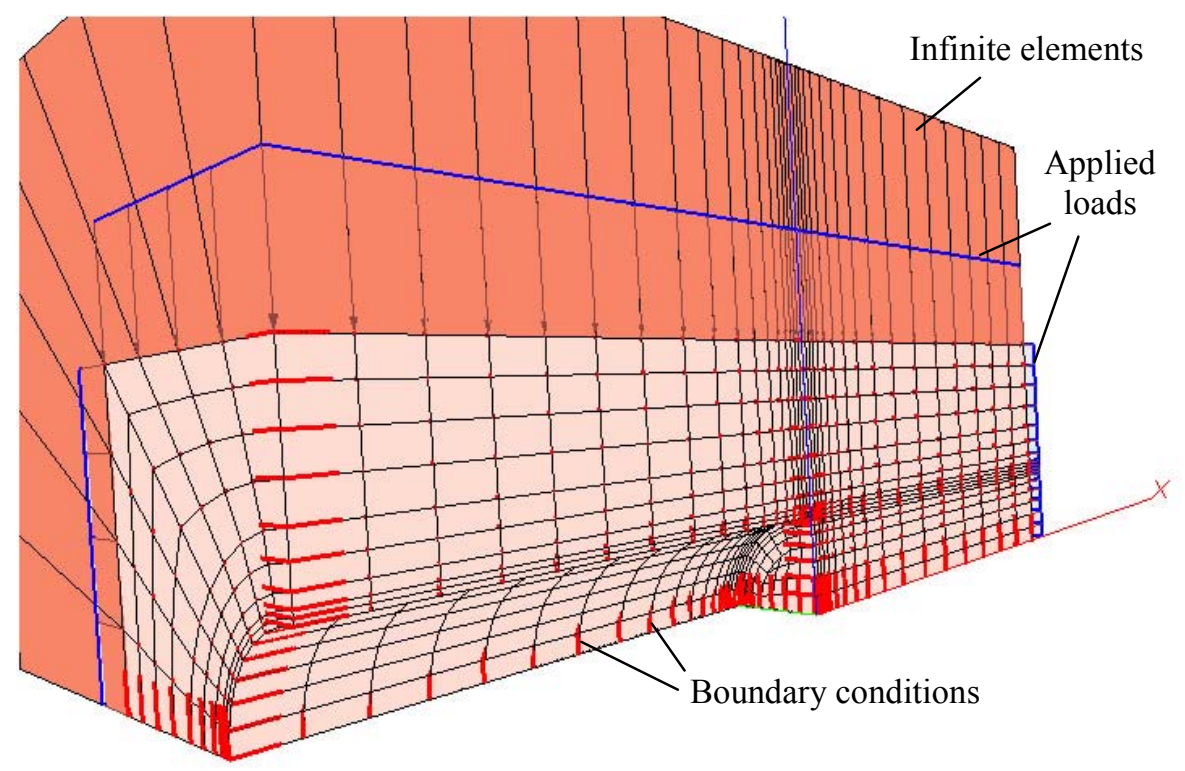

Fig. 8. The 3D finite element model used for this research (note: red lines for boundary conditions indicate the direction of zero displacement)

\subsubsection{Calculations for TM 3700 and influence} of stress assumption

As the flat-jack test (see Section 3.1) had been performed at TM 3700, not very far from a failure zone, the first numerical calculations used the corresponding stress conditions in order to:

- compare field observation, semi-empirical failure criterion and Z_Soil calculations with the brittle Hoek-Brown parameters;

- assess the influence of the longitudinal stress value ${\sigma_{X}}^{0}$ on the predictions of wall stability.

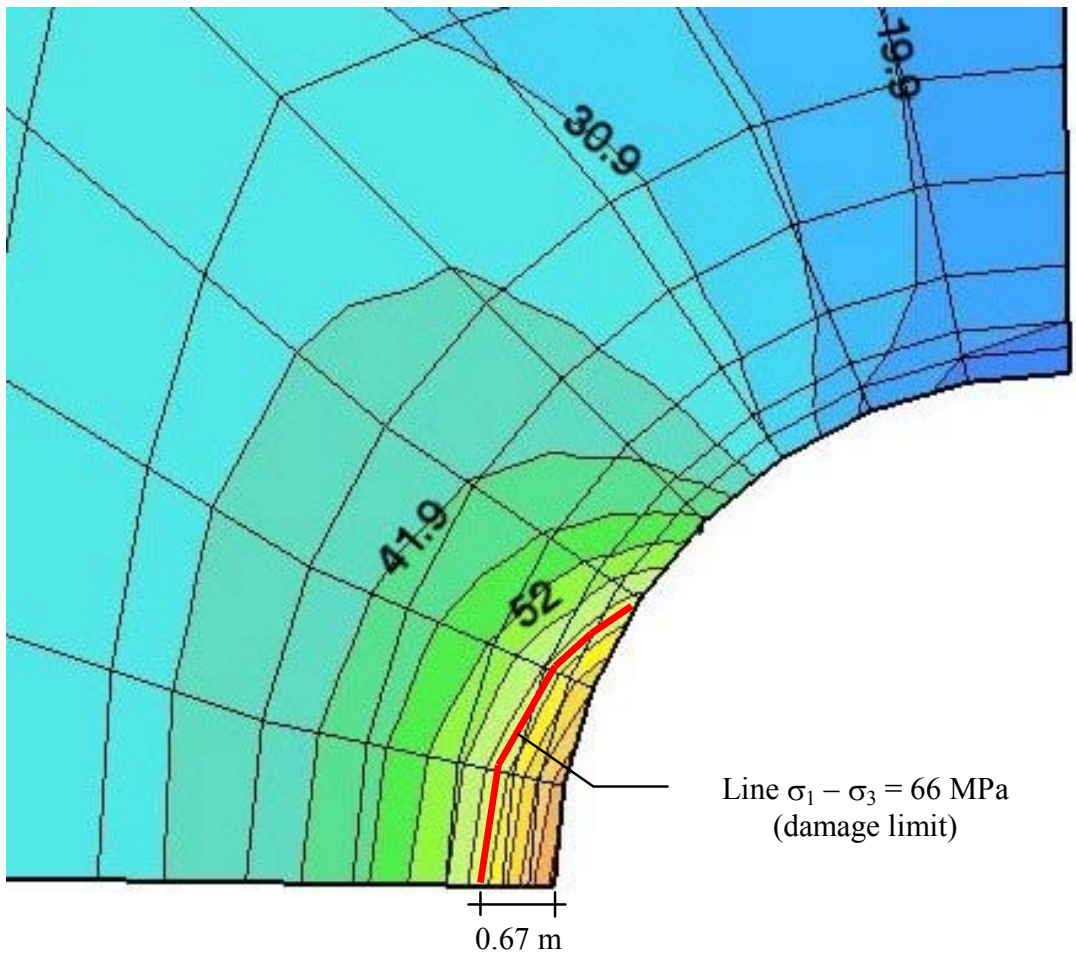

Fig. 9. Plot of $\sigma_{1}-\sigma_{3}$ (in MPa) for a tunnel section far behind the face, under far-field stresses $\sigma_{\mathrm{Z}}{ }^{0}=38 \mathrm{MPa}, \sigma_{\mathrm{Y}}{ }^{0}=13 \mathrm{MPa}$ and $\sigma_{\mathrm{X}}{ }^{0}=9 \mathrm{MPa}$, at TM 3700 (granite) 
The first calculation used the far-field stresses predicted by IGWS (1995), i.e.: $\sigma_{\mathrm{Z}}{ }^{0}=38 \mathrm{MPa},{\sigma_{\mathrm{Y}}}^{0}=$ $13 \mathrm{MPa}, \sigma_{\mathrm{X}}{ }^{0}=9 \mathrm{MPa}$. The rock type is granite, with UCS $=200 \mathrm{MPa}$ (see Table 2). The results are presented in Figure 9 for a tunnel section far behind the face. The isovalues represent the deviator $\sigma_{1}-\sigma_{3}$, given in $\mathrm{MPa}$. Referring to the brittle Hoek-Brown parameters, failure may be observed when $\sigma_{1}-\sigma_{3}>$ 0.33 UCS i.e. in this case $\sigma_{1}-\sigma_{3}>66 \mathrm{MPa}$. The maximum depth of failure is predicted in the walls with a value of $0.67 \mathrm{~m}$. This value is in good agreement with the observed failure (around $0.6 \mathrm{~m}$ ) and with the failure predicted in Section 4.1 ( $0.58 \mathrm{~m}$ with the semi-empirical criterion). The predicted lateral extent of the notch also appears to be in good agreement with the field observations.

To assess the influence of a possible tectonic stress parallel to the tunnel axis, a second simulation was carried out with the longitudinal far-field stress value $\sigma_{X}{ }^{0}=15 \mathrm{MPa}$, as obtained by the flat-jack test. The depth of failure and lateral extent of the notch are almost the same as in Figure 9. As for the depth of failure itself, a value of $0.64 \mathrm{~m}$ (instead of $0.67 \mathrm{~m}$ ) is predicted with $\sigma_{X}{ }^{0}=15 \mathrm{MPa}$. This very small difference shows that the uncertainty on the $\sigma_{X}{ }^{0}$ value does not affect the stability prediction of the tunnel walls, as it is primarily driven by maximum tangential stress. Consequently, other simulations of wall behaviour were simply performed with the far-field stress values from the IGWS (1995).

\subsubsection{Additional analyses}

In order to evaluate the quality of depth-of-failure assessment with rock types other than granite, further simulations were run with the predicted stress conditions at different locations, as detailed in Table 2.

Table 2 Data for Z_Soil FEM calculations at various locations along the Steg track (far-field stresses from the IGWS (1995)).

\begin{tabular}{lllllll}
$\begin{array}{l}\text { Tunnel } \\
\text { meter }\end{array}$ & Rock type & $\begin{array}{l}\text { UCS } \\
(\mathrm{MPa})\end{array}$ & $\begin{array}{l}\mathrm{UCS} / 3 \\
(\mathrm{MPa})\end{array}$ & $\begin{array}{l}\sigma_{\mathrm{Z}}{ }^{0} \\
(\mathrm{MPa})\end{array}$ & $\begin{array}{l}\sigma_{\mathrm{Y}}{ }^{0} \\
(\mathrm{MPa})\end{array}$ & $\begin{array}{l}\sigma_{\mathrm{X}}{ }^{0} \\
(\mathrm{MPa})\end{array}$ \\
\hline TM 1200 & Gneiss & 95 & 32 & 13 & 7 & 13 \\
TM 1610 & Gneiss & 95 & 32 & 18 & 8 & 12 \\
TM 2500 & Granodiorite & 140 & 46 & 28 & 10 & 10 \\
\hline
\end{tabular}

The corresponding results listed in Table 3, clearly show a good agreement between the depths of failure (D.o.F.) predicted with elastic simulations and brittle Hoek-Brown criteria, or the semi-empirical criterion. As shown in Section 4.1, these results are also in good agreement with observed failures in the tunnel.

Table 3 Comparison between predicted depths of failure (D.o.F.) along the Steg track with two different failure criteria.

\begin{tabular}{llll}
$\begin{array}{l}\text { Tunnel } \\
\text { meter }\end{array}$ & Rock type & $\begin{array}{l}\text { D.o.F. semi- } \\
\text { empirical criterion }\end{array}$ & $\begin{array}{l}\text { D.o.F. brittle Hoek-Brown } \\
\text { (elastic Z_Soil calculation) }\end{array}$ \\
\hline TM 1200 & Gneiss & $0 \mathrm{~m}$ & $0 \mathrm{~m}$ \\
TM 1610 & Gneiss & $0.41 \mathrm{~m}$ & $0.49 \mathrm{~m}$ \\
TM 2500 & Granodiorite & $0.73 \mathrm{~m}$ & $0.66 \mathrm{~m}$ \\
TM 3700 & Granite & $0.58 \mathrm{~m}$ & $0.67 \mathrm{~m}$ \\
\hline
\end{tabular}

\subsection{Concluding remarks about wall failure}

The good quality of the results obtained in Sections 4.1 and 4.2 for tunnel walls shows that the observed phenomena at the Lötschberg base tunnel are correctly depicted with spalling mechanisms. The two methods tested (semi-empirical criterion and brittle Hoek-Brown parameters with elastic Z_Soil FE calculations) to assess the depth of failure provide quite similar results, and these results fit well with observed conditions. This demonstrates that the approaches developed from the experiments at the Canadian URL and experiences from tunnels around the world (see Section 2) seem to apply correctly to the brittle rocks encountered in the Lötschberg base tunnel. Consequently, such analyses would be of great interest for actual and future tunnel projects in brittle rocks: they should allow the reliable prediction of the spalling and strain-bursting potential and severity that may be encountered during the tunnelling process.

However, it must be emphasised that these evaluation methods are only applicable for massive to moderately jointed rock masses. In case of a high fracture degree, the rock mass may show a more plastic 
behaviour as more deformation is permitted. Failure may then be assessed with classical yield criteria. At the Lötschberg base tunnel, this remark was confirmed by the observation of some disturbed zones in highly fractured areas (decimetric average joint spacing) during the extensive review of wall damage performed for this research.

\section{Growth of failure along the tunnel and indications for support systems}

As a complementary analysis, $3 \mathrm{D}$ calculations of the deviatoric stress contours $\sigma_{1}-\sigma_{3}$ have also been conducted in order to highlight the mechanisms of damage initiation and failure growth along the tunnel wall.

It must be noted beforehand that the finite element simulations presented hereafter are overly simplistic to analyse face stability. Indeed, they ignore the mechanics of spalling (cohesion loss favouring fracture extension that are reflected in a spalling limit) that play a significant role at the face due to the 3D nature of the stress conditions. In particular, Kaiser (2005) and Kaiser (2006) showed with non-elastic models using brittle parameters that, contrary to the limited zone of failure that could be inferred from Figure 10, for instance, spalling at the face may occur at the Lötschberg base tunnel at stresses less than those required to cause failure at the walls.

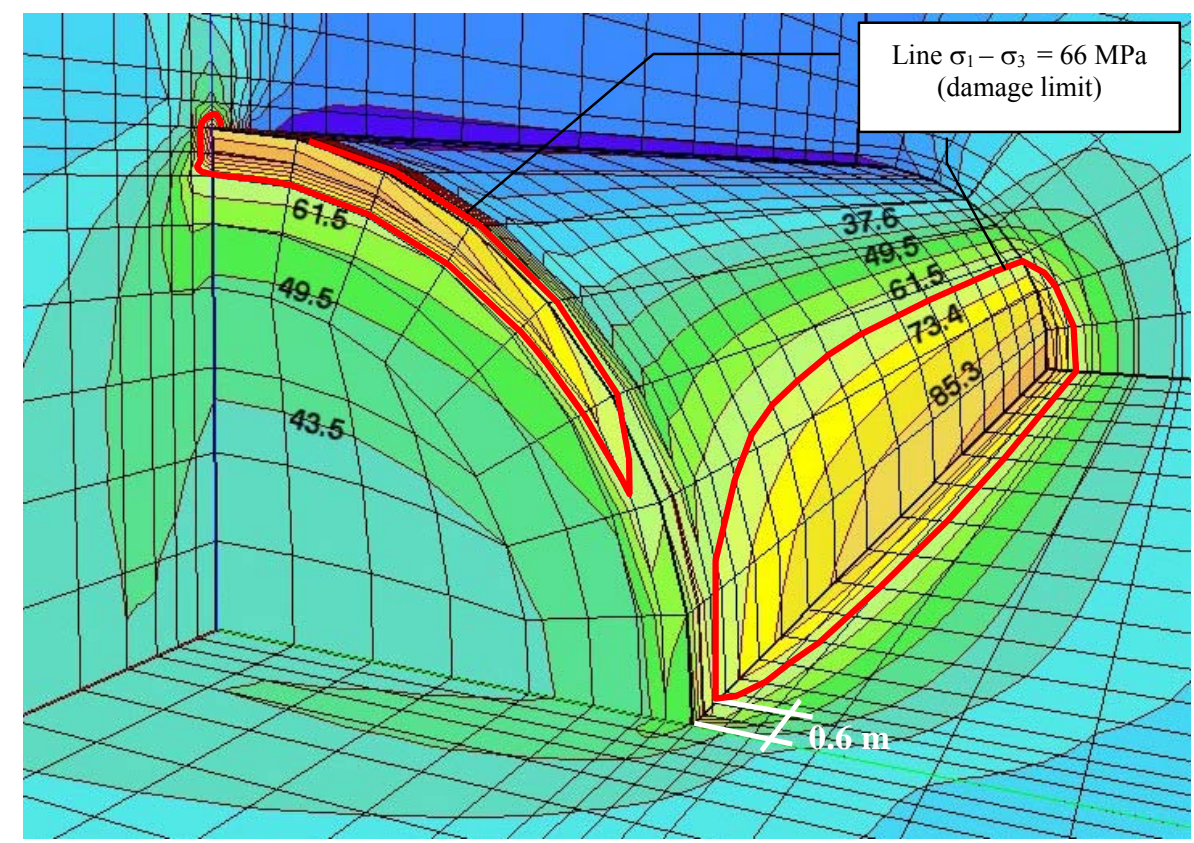

Fig. 10. Plot of $\sigma_{1}-\sigma_{3}$ (in MPa) around the face, under far-field stresses : $\sigma_{\mathrm{Z}}{ }^{0}=38 \mathrm{MPa}, \sigma_{\mathrm{Y}}{ }^{0}=13 \mathrm{MPa}$ and $\sigma_{\mathrm{X}}{ }^{0}=15 \mathrm{MPa}$, at $\mathrm{TM}$ 3700 (granite)

Figure 10 presents the results of an elastic analysis of the stress conditions near the tunnel face, showing that some damage is initiated at the border of the face because of stress concentrations due to the corner effect $\left(\sigma_{1}-\sigma_{3}\right.$ exceeds the damage limit $\left.\mathrm{UCS} / 3 \approx 66 \mathrm{MPa}\right)$. This first damage mechanism is especially observed near the roof and floor of the tunnel. However, it does not necessarily lead to spalling behind the face because of the fast decrease in stresses that occurs in the first metres of excavation. As a consequence, the rock in the roof and floor of the tunnel may be damaged ("crack initiation" i.e. microcracks) but not failed (no coalescence).

On the walls, the scenario is different. The simulations do not show any failure initiation at the face corner $\left(\sigma_{1}-\sigma_{3}<\mathrm{UCS} / 3\right)$. Nevertheless, some high stresses exist in this zone due to corner effects and rock may be damaged anyway in a very shallow area. After this potential initiation at the face border, failure is not encountered until the tangential stress reaches sufficiently high values in the walls such that $\sigma_{1}-\sigma_{3}$ exceeds UCS/3. As shown in Figure 10, representing typically unfavourable spalling conditions for the tunnel walls at the Lötschberg, this latter condition is reached in the walls within the first metre behind the face (this limit tends to move away from the face when more favourable stress conditions are encountered). After this spalling-initiation limit, the depth of failure increases progressively until it 
reaches, at about one tunnel diameter behind the face, the maximum value that corresponds to the depth of failure given in section 4.

This description of stress conditions near the face and from the face to the walls is in good agreement with the simulations from Eberhardt (2001) in a lithostatic case. Eberhardt also highlighted the phenomenon of stress rotation near the face, provoking increased stress-induced brittle fracture damage.

More generally, these observations back the propositions by Kaiser et al. (2000): rock support to control brittle damage, such as fully grouted rebar, should be added within the first few meters behind the face to prevent the bulking phenomenon related to brittle rock failure. A complementary yielding support system should be added then, when violent failure, i.e. strainbursting, is encountered. The support requirements may then be assessed in a two-step process:

- first step: based on the recommendations from Kaiser et al. (2000) evaluate the support characteristics that should ensure deformation compatibility of support and ground. The main idea of this step is that the stress reduction factor (Barton, 1994) provides an indirect means to account for bulking. A stability chart can then be used to evaluate support requirements.

- second step: considering the case when a strain-burst occurs, identify appropriate support to deal with rock ejection.

In the authors' opinion, such considerations should be taken into account at the level of both project studies and TBM conception for tunnels excavated within a burst-prone environment.

\section{Conclusion}

In this research, the hard rock failures observed in the Lötschberg base tunnel along the Steg lateral adit have been analysed. In particular, the developments from Canadian experience (A.E.C.L. Underground Research Laboratory) in the theory of brittle failure, including a semi-empirical failure criterion and brittle Hoek-Brown parameters, have been used and compared with field observations.

At the tunnel walls, the notch formation process is well explained by spalling mechanisms: the depthof-failure predictions with both the semi-empirical failure criterion and the so-called "brittle HoekBrown" model are in good agreement with the observed phenomena. The variability in overbreak can be attributed to several factors, including variability in rock strength (UCS) and/or brittleness of the encountered rock formations, fracture density, in-situ stresses, etc. When the depth of failure is determined with mean values, there is, by definition, a 50:50 chance that in reality less (or more) failure is encountered. This is reflected by the fact that no failure is sometimes encountered between areas showing distress.

Several difficulties were encountered when applying these methods from the Canadian URL experiment to the Lötschberg base tunnels. One of the limits lies in the quality of the UCS estimations. In particular, the UCS values have to be evaluated on intact rock specimens, i.e. without pre-existing damage generated by the tunnel excavation and/or coring processes. This condition may lead to a more systematic use of damage detection methods such as acoustic monitoring in laboratory tests. Concerning the brittle Hoek-Brown parameters, rock characterisation could also be deepened in order to take into account factors such as rock brittleness (Hajiabdolmajid et al., 2002) in the evaluation of the damage threshold.

The necessity for reliable in situ stresses measurements constitutes an additional difficulty. The evaluations from 3-D topographic models may, indeed, be insufficient as the presence of large faults, the heterogeneity of the rigidity of the rock formations or the existence of tectonic stresses can play an important role in the resulting rock mass behaviour.

Near the face, the 3D calculations performed in this paper helped highlighting the kinematics of brittle failure growth along the tunnel walls. They also confirmed the limitations of simple elastic analysis, that are usually sufficient to evaluate wall spalling, in order to assess face stability.

More generally, the results presented provide further support for the Canadian approach of brittle failure analysis, and stress a list of important parameters for deep tunnels in a burst-prone environment. They highlight the interest to perform such studies in the early stages of project conception in order to allow the selection of adapted excavation techniques and support systems.

\section{Acknowledgements}

The authors wish to thank BLS AlpTransit and AlpTransit Gotthard for their financial support and permission to publish the paper. They also thank I.G.W.S. (Ingenieur-Gemeinschaft WestSchweiz) who allowed this research programme to be carried out by making it easier to investigate the tunnel and to consult the previously written documents. 


\section{References}

Barton N. (1994): A Q-System case record of cavern design in faulted rock, Tunnelling in Difficult Ground, Torino, Italy, $8 \mathrm{p}$.

Diederichs M.S., Kaiser P.K. and Eberhardt E. (2004): Damage initiation and propagation in hard rock during tunnelling and the influence of near-face stress rotation. International Journal of Rock Mechanics and Mining Science, 41 (5), pp. 785-812.

Diederichs M.S., Kaiser Peter K. and Martin Derek C. (2000): The use of discrete element simulation to illuminate brittle rock failure process, 53rd Canadian Geotechnical Conference, pp. 447-454, Montreal.

Eberhardt E. (2001): Numerical modelling of three-dimensional stress rotation ahead of an advancing face. International Journal of Rock Mechanics and Mining Science, 38, pp. 499-518.

Griffith A.A. (1924): Theory of rupture, 1st International Congress Applied Mechanics, pp. 55-63, Delft.

Hajiabdolmajid V.R., Kaiser Peter K. and Martin Derek C. (2003): Mobilised strength components in brittle failure of rock. Geotechnique, 53 (3), pp. 327-336.

Hajiabdolmajid V.R., Kaiser Peter K. and Martin Derek C. (2002): Modelling brittle failure of rock. International Journal of Rock Mechanics and Mining Science, 39, pp. 731-741.

Horii H. and Nemat-Nasser S. (1985): Compression-induced microcrack growth in brittle solids: axial splitting and shear failure. Journal of Geophysical Research, 90 (B4), pp. 3105-3125.

IGWS (1995): Décompressions violentes : évaluation des zones à risques. Report RA14 for BLS AlpTransit AG Lötschberg Basislinie, $155 \mathrm{p}$.

Kaiser, Peter K. (2006): Rock mechanics consideration for construction of deep tunnel in brittle ground. Keynote lecture, Asian Rock Mechanics Symposium, Singapore, 12 p.

Kaiser, Peter K. (2005): Tunnel stability in highly stressed, brittle ground - Rock mechanics considerations for Alpine tunnelling. Keynote lecture, Geological AlpTransit Symposium GEAT'05, Zürich, Switzerland, 20 p.

Kaiser Peter K. (2002): Lötschberg tunnel: rockburst hazard assessment - Contribution to project R487. MIRARCO, Laurentian University, 22 p.

Kaiser Peter K., Diederichs M.S., Martin Derek C., Sharp J. and Steiner W. (2000): Underground Works in Hard Rock Tunnelling and Mining. Keynote lecture at GeoEng2000, Technomic Publishing Co. Eds., pp. 841-926, Melbourne, Australia.

Kaiser, Peter K., McCreath D.R., and Tannant, D.D. (1996): Canadian Rockburst Support Handbook, Sudbury, ON: Mining Research Directorate, $314 \mathrm{p}$.

Martin Derek C. (1997): Seventeenth Canadian Geotechnical Colloquium: The effect of cohesion loss and stress path on brittle rock strength. Canadian Geotechnical Journal, 34 (5), pp. 698-725.

Martin Derek C., Kaiser Peter K. and Christiansson R. (2003): Stress, instability and design of underground excavations. International Journal of Rock Mechanics and Mining Science, 40, pp. 1027-1047.

Martin Derek C., Kaiser Peter K. and McCreath D.R. (1999): Hoek-Brown parameters for predicting the depth of brittle failure around tunnels. Canadian Geotechnical Journal, 36 (1), pp. 136-151.

Martin Derek C. and Stimpson B. (1994): The effect of sample disturbance on laboratory properties of Lac du Bonnet granite. Canadian Geotechnical Journal, 31 (5), pp. 692-702.

Müller B., Reinecker J., Heidbach O. and Fuchs K. (2004): The 2004 release of the World Stress Map. Available online at www.world-stress-map.org.

Rojat F., Labiouse V., Descoeudres F. and Kaiser Peter K. (2002): Brittle rock failure at the Loetschberg, Steg sector (AlpTransit tunnel). Report R487. Rock Mechanics Laboratory of EPFL, Lausanne.

Z_Soil V.5.71 (2002): User's manual. ZACE, Lausanne, Switzerland. 